\title{
On-Line Electrochemistry/Liquid Chromatography/Mass Spectrometry for the Simulation of Pesticide Metabolism
}

\author{
Wiebke Lohmann, ${ }^{\mathrm{a}}$ Reinhard Dötzer, ${ }^{\mathrm{b}}$ Gerald Gütter, ${ }^{\mathrm{b}}$ \\ Suze M. Van Leeuwen, ${ }^{a}$ and Uwe Karst ${ }^{a}$ \\ ${ }^{a}$ Westfälische Wilhelms-Universität Münster, Institute of Inorganic and Analytical Chemistry, Münster, Germany \\ b BASF SE, Agricultural Center Limburgerhof, Global Analytics, Limburgerhof, Germany
}

On-line electrochemistry/liquid chromatography/mass spectrometry (EC/LC/MS) was employed to mimic the oxidative metabolism of the fungicide boscalid. High-resolution mass spectrometry and MS/MS experiments were used to identify its electrochemical oxidation products. Furthermore, the introduction of a second electrochemical cell with reductive conditions provided important additional information on the oxidation products. With this equipment, hydroxylation, dehydrogenation, formation of a covalent ammonia adduct, and dimerization were detected after initial one-electron oxidation of boscalid to a radical cation. On-line reaction with glutathione yielded different isomeric covalent glutathione adducts. The results of the electrochemical oxidation are in good accordance with previously reported in vivo experiments, showing that EC/LC/MS is a useful tool for studying biotransformation reactions of various groups of xenobiotics. (J Am Soc Mass Spectrom 2009, 20, 138-145) (c) 2009 Published by Elsevier Inc. on behalf of American Society for Mass Spectrometry

$\mathrm{T}$ The on-line coupling of electrochemistry with mass spectrometry (EC/MS) was introduced more than 20 years ago for studying redox reactions of various substances including biomolecules [1-5]. Soon it became clear that this newly developed technique offers interesting features for the simulation of drug metabolism. While off-line electrochemical models for cytochrome P450 metabolism reactions were investigated by Shono et al. [6, 7], and Hanzlik et al. [8, 9], Getek et al. reported first achievements in the on-line coupling of electrochemistry to mass spectrometry for the simulation of drug metabolism [10]. They studied the electrochemical oxidation of paracetamol to $N$-acetyl-p-quinoneimine in a commercially available flow-through cell comprising a glassy carbon working electrode with a large surface area and the subsequent reaction of the quinoneimine with the bioavailable thiols glutathione and cysteine. After several years, during which hardly any attention was paid to this field of research, the group of Bruins systematically investigated the similarities and differences of electrochemical and cytochrome P450 catalyzed reactions on different classes of compounds [11, 12] and identified which cytochrome $P 450$ reactions can be mimicked electrochemically. Gamache et al. looked into the potential of on-line EC/MS from an industrial point of view and highlighted the relevance of this

Address reprint requests to Dr. U. Karst, Institute of Inorganic and Analytical Chemistry, Corrensstr. 30, 48149 Münster, Germany. E-mail: uk@uni-muenster.de purely instrumental and rapid screening technique for ADME/Tox-profiling and other metabolomics applications $[13,14]$. However, no information except that from MS experiments was accessible about the oxidation products. Therefore, the on-line EC/MS system was expanded by introduction of an HPLC separation of the oxidation products before MS analysis (EC/LC/MS). Using this set-up, valuable information on the polarity of the oxidation products and on the formation of different isomers can be obtained, as was shown in our group for the antipsychotic agent clozapine [15] and for paracetamol [16]. Particularly for the investigation of reactive metabolites, on-line EC/LC/MS proved to offer some interesting aspects concerning the preparation [17] and the direct detection of short-lived species that often cannot be seen in biological systems [18]. Detailed information on the state-of-the-art in the field of EC/MS and $\mathrm{EC} / \mathrm{LC} / \mathrm{MS}$ has been published in recent reviews [19-21].

As can be seen from these publications, up to now all efforts in this field of research were directed towards the simulation of the metabolism of pharmaceuticals. Nothing, however, is reported about the electrochemical simulation of pesticide metabolism. The metabolism of newly developed pesticides is often investigated in animals or plants in vivo using radiolabeled parent compounds. Simulation techniques could offer an interesting supplement to standard techniques that can be applied in an early stage of the development process since they deliver rapid information about oxidatively labile positions in a molecule and enable the
(C) 2009 Published by Elsevier Inc. on behalf of American Society for Mass Spectrometry. $1044-0305 / 09 / \$ 32.00$

doi:10.1016/j.jasms.2008.09.003
Published online September 7, 2008 Received July 24, 2008 Revised September 1, 2008 Accepted September 1, 2008 
detection of short-lived species. Therefore, the pesticide boscalid was selected as model compound for the electrochemical simulation of the oxidative metabolism of xenobiotics.

The carboximide fungicide boscalid (2-chloro- $N$ (4' -chloro(1,1'-biphenyl)-2-yl)-3-pyridinecarboxamide, Scheme 1) is a versatile, broad-spectrum, and highly environmentally compatible fungicide ideal for use in high-end specialty crops such as fruit, vegetables, wine, and horticultural plants. It has a broad spectrum of action against most fungal diseases affecting these crops, and in combination with other fungicides in a wide variety of other crops as well. The metabolic pathway of boscalid includes the formation of different hydroxylated species and glutathione (GSH) adducts [22]. GSH adduct formation is described to proceed either by nucleophilic substitution of the chlorine atom at ring A (Scheme 1a) or after arene oxide formation as phase I metabolism step and subsequent nucleophilic attack of GSH to the arene oxide resulting in different isomeric species (Scheme 1b). The first process is followed by manifold biodegradation of the GSH moiety by loss of amino acid residues and $S$-oxidation processes, as found in animal studies in vivo in rats.

\section{Experimental}

\section{Chemicals}

Boscalid and $p$-hydroxyboscalid were obtained from BASF SE Agricultural Center, Limburgerhof, Germany. Formic acid was obtained from Fluka Chemie $\mathrm{GmbH}$ (Buchs, Switzerland). Reduced L-glutathione was purchased from Sigma-Aldrich Chemie GmbH (Steinheim, Germany). Acetonitrile for HPLC was obtained from Merck KGaA (Darmstadt, Germany). All chemicals were used in the highest quality available. Water used for HPLC was purified using a Milli-Q Gradient A 10 system and filtered through a $0.22 \mu \mathrm{M}$ Millipak 40 (Millipore, Billerica, MA).

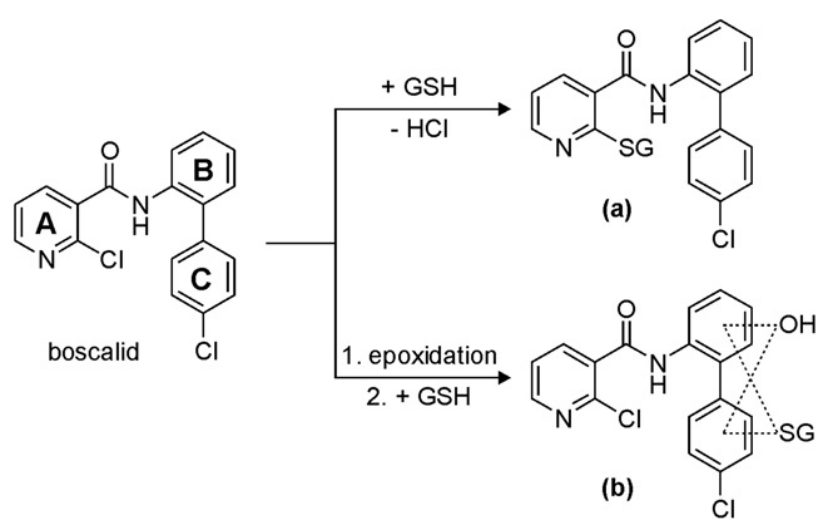

Scheme 1. Structure of boscalid and Phase I and II metabolism in vivo.

\section{Instrumentation}

The electrochemical equipment was mainly obtained from ESA Biosciences Inc. (Chelmsford, MA). It consisted of a model 5020 guard cell or a model 5021 conditioning cell, and a Coulochem II or a home-made potentiostat. The EC cells contain a glassy carbon working electrode, a Pd counter electrode and a $\mathrm{Pd} / \mathrm{H}_{2}$ reference electrode. A PEEK in-line filter was placed in front of the guard cell inlet to protect the working electrode. For LC/MS measurements, a Shimadzu HPLC system (Duisburg, Germany) comprising two LC-10AD $v-p$ pumps, a DGC14A degasser, a SIL-HTa autosampler, a CTO-10Av- $p$ column oven and a SPD-10AVv- $p$ UV detector was coupled to a QTRAP mass spectrometer from Applied Biosystems (Darmstadt, Germany) or a micrOTOF mass spectrometer from Bruker Daltonics (Bremen, Germany), both equipped with an electrospray ionization (ESI) source. The software used for controlling HPLC and QTRAP was Analyst 1.4.1 (Applied Biosystems). For controlling the micrOTOF and data handling, micrOTOFControl 1.1 and dataAnalysis 3.3 (Bruker Daltonics) software were used.

\section{Electrochemical Conditions}

For the electrochemical oxidation, a $50 \mu \mathrm{M}$ solution of boscalid in ammonium formate solution (20 mM, pH adjusted to 7.4 with ammonium hydroxide solution) and acetonitrile (50/50, vol/vol) was used. The solution was pumped through the EC guard cell model 5020 using a syringe pump model 74,900 (Cole Parmer, Vernon Hills, IL) at a flow rate of $10 \mu \mathrm{L} / \mathrm{min}$. For EC/MS experiments, the effluent of the EC cell was directed into the ESI source of the mass spectrometer (Figure 1a). The potential at the working electrode of the EC cell was ramped from 0 to $2000 \mathrm{mV}$ versus $\mathrm{Pd} / \mathrm{H}_{2}$ within $12 \mathrm{~min}(167 \mathrm{mV} / \mathrm{min})$ using the homemade potentiostat. For EC/LC/MS measurements, the working electrode of the EC cell was kept at a constant potential and the system was allowed to equilibrate for 5 min after switching on the EC cell. Depending on the experiment, three different approaches were used. For only oxidation experiments, the effluent from the EC cell was collected directly in a $10 \mu \mathrm{L}$ loop which was mounted on a ten-port switching valve (Figure 1b, flow path A). For reduction of the oxidation products, the flow from the first EC cell was directed through a second EC cell (conditioning cell model 5021) in which the oxidation products were reduced at $-1000 \mathrm{mV}$ versus $\mathrm{Pd} / \mathrm{H}_{2}$ (Figure $1 \mathrm{~b}$, flow path $\mathrm{B}$ ). For studying the formation of covalent GSH adducts, GSH (500 $\mu \mathrm{M}$ in 20 $\mathrm{mM}$ ammonium formate solution, $\mathrm{pH}$ adjusted to 7.4 with ammonium hydroxide) was added through a T-piece using a second syringe pump at the same flow rate after the first EC cell (Figure 1b, flow path C). After the equilibration time of the total system of about $5 \mathrm{~min}$, the EC effluent was injected onto the HPLC column by switching the 10-port valve. 

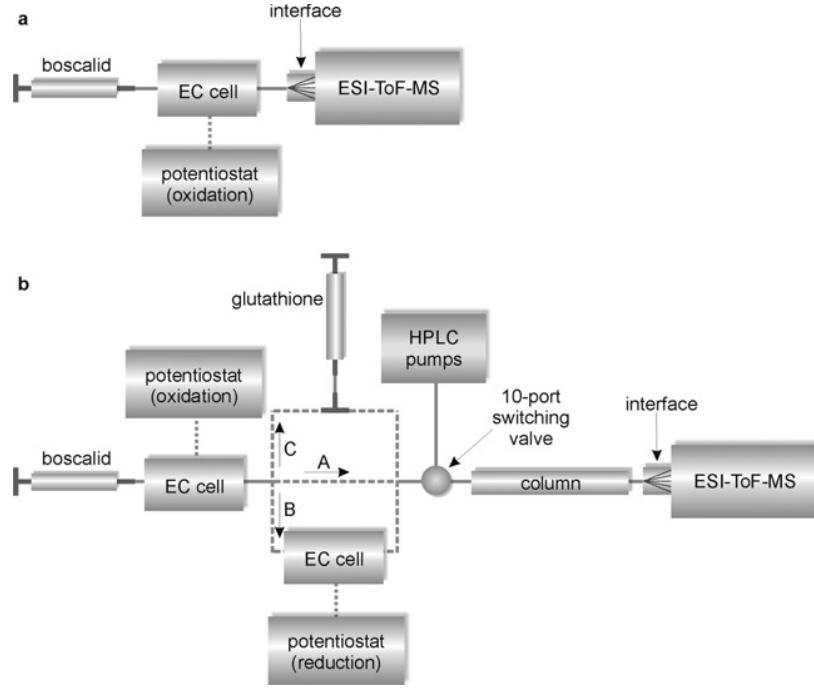

Figure 1. (a) Schematic set-up of the EC/MS system. (b) Schematic set-up of the EC/LC/MS system. Flow path A: injection after oxidation of boscalid; B: injection after oxidation of boscalid and reduction of the oxidation products; $\mathrm{C}$ : injection after oxidation of boscalid and reaction with glutathione.

\section{HPLC Conditions}

Separation of boscalid and its oxidation products and GSH adducts was performed on a ZORBAX Eclipse $\mathrm{XDB}_{-\mathrm{C}_{18}}$ column $(50 \times 2.1 \mathrm{~mm}, 3.5 \mu \mathrm{M}$ particle size, Agilent, Waldbronn, Germany). The column was kept at a temperature of $40{ }^{\circ} \mathrm{C}$ during the separation and the flow rate of the mobile phase was $0.3 \mathrm{~mL} / \mathrm{min}$. Eluent $\mathrm{A}$ of the mobile phase was $0.1 \%$ formic acid in deionized water and eluent B was acetonitrile. The injection volume was $10 \mu \mathrm{L}$ (loop size). The gradient profile for the separation is shown in Table 1.

\section{MS Conditions}

On the micrOTOF instrument, full scan spectra $(\mathrm{m} / \mathrm{z}$ 150-1000) were recorded after HPLC separation using $\mathrm{ESI}(+)-\mathrm{MS}$ under the following conditions: end plate offset: $-500 \mathrm{~V}$, capillary: $4000 \mathrm{~V}$, nebulizer gas $\left(\mathrm{N}_{2}\right)$ : 0.8 bar, drying gas $\left(\mathrm{N}_{2}\right): 8.0 \mathrm{~L} / \mathrm{min}$, drying temperature: $200{ }^{\circ} \mathrm{C}$, capillary exit: $150.0 \mathrm{~V}$, skimmer 1: $50.0 \mathrm{~V}$, skimmer 2: 23.0 V, hexapole 1: $24.0 \mathrm{~V}$, hexapole 2: 20.6 $\mathrm{V}$, hexapole RF: $75 \mathrm{~V}$, transfer time: $49.0 \mu \mathrm{s}$, pre-pulse storage: $2.0 \mu \mathrm{s}$, detector: $-1000 \mathrm{~V}$. For direct infusion using the syringe pump at a flow rate of $10 \mu \mathrm{L} / \mathrm{min}$, the parameters were the same except nebulizer gas $\left(\mathrm{N}_{2}\right)$ : 0.4 bar, drying gas $\left(\mathrm{N}_{2}\right): 4.0 \mathrm{~L} / \mathrm{min}$ and drying temperature: $180^{\circ} \mathrm{C}$. Internal calibration was performed using sodium formate clusters at the beginning of each HPLC run. On the QTRAP instrument, ESI(+)-MS/MS was performed using the linear ion trap in enhanced product ion mode. The following settings were used: nebulizer gas: 50 psi, dry gas/heating gas: 70 psi, temperature: $400^{\circ} \mathrm{C}$, ionspray voltage: $5500 \mathrm{~V}$, declustering potential: $30 \mathrm{~V}$, entrance potential: $10 \mathrm{~V}$, CAD gas pressure: "high", collision energy: $35 \mathrm{~V}$, collision energy spread: $15 \mathrm{~V}$.

\section{Results and Discussion}

\section{Electrochemical Oxidation of Boscalid}

Initially, EC/MS experiments without liquid chromatographic separation were performed to obtain information on the electrochemical oxidation behavior of boscalid. Therefore, a commercially available electrochemical flow-through cell comprising a porous glassy carbon working electrode, a palladium counter electrode, and a $\mathrm{Pd} / \mathrm{H}_{2}$ reference electrode was employed. The porosity of the working electrode allows up to $100 \%$ conversion of the analytes to their electrochemical oxidation (or reduction) products. Therefore, this cell type is referred to as "coulometric cell". A solution of boscalid was filled into a syringe and was pumped at a flow rate of $10 \mu \mathrm{L} / \mathrm{min}$ through the EC cell. The effluent of the cell was directed into the ESI interface of the time-of-flight (TOF) mass spectrometer (Figure 1a). To mimic the physiological conditions as far as possible, the oxidation was carried out at $\mathrm{pH}$ 7.4. However, an organic modifier was required to prevent the analytes from adsorbing to the surface of the working electrode; therefore, $50 \%$ of acetonitrile were added to the solution. The electrochemical potential of the working electrode was ramped from 0 to $2000 \mathrm{mV}$ versus $\mathrm{Pd} / \mathrm{H}_{2}$ in $12 \mathrm{~min}$ (equivalent to a slope of $167 \mathrm{mV} / \mathrm{min}$ ) using a home-made potentiostat. Full scan mass spectra in an $m / z$ range of $150-1000$ in positive-ion mode were recorded. Before oxidation, protonated boscalid showing the typical chlorine isotopic pattern is observed as base peak in the mass spectrum, and only a minor peak of the respective noncovalent sodium adduct, which is formed in the ESI source is observed (Supplemental Figure 1, which can be found in the electronic version of this article). The accurate $m / z$ of $343.03,967$ is in good accordance with the theoretical value of $343.03,995$ (0.816 ppm error). In Figure 2a, the smoothed ion intensity of the boscalid $[\mathrm{M}+\mathrm{H}]^{+}$signal with $\mathrm{m} / z 343$ is plotted against the oxidation potential. At $1000 \mathrm{mV}$ versus $\mathrm{Pd} / \mathrm{H}_{2}$, the signal intensity starts to decrease; thus, the oxidation of boscalid begins in the range of this potential. At about $1300 \mathrm{mV}$, the minimum signal intensity is reached and a small but stable residual intensity of the protonated boscalid is observed. Figure 3 shows the mass spectrum of boscalid after oxidation

Table 1. Gradient profile for the HPLC separation

\begin{tabular}{|c|c|c|c|c|c|c|}
\hline Time [min] & 0.00 & 1.00 & 10.00 & 11.00 & 11.01 & 15.00 \\
\hline$\% \mathrm{~B}(\mathrm{ACN})$ & 10 & 10 & 95 & 95 & 10 & Stop \\
\hline
\end{tabular}



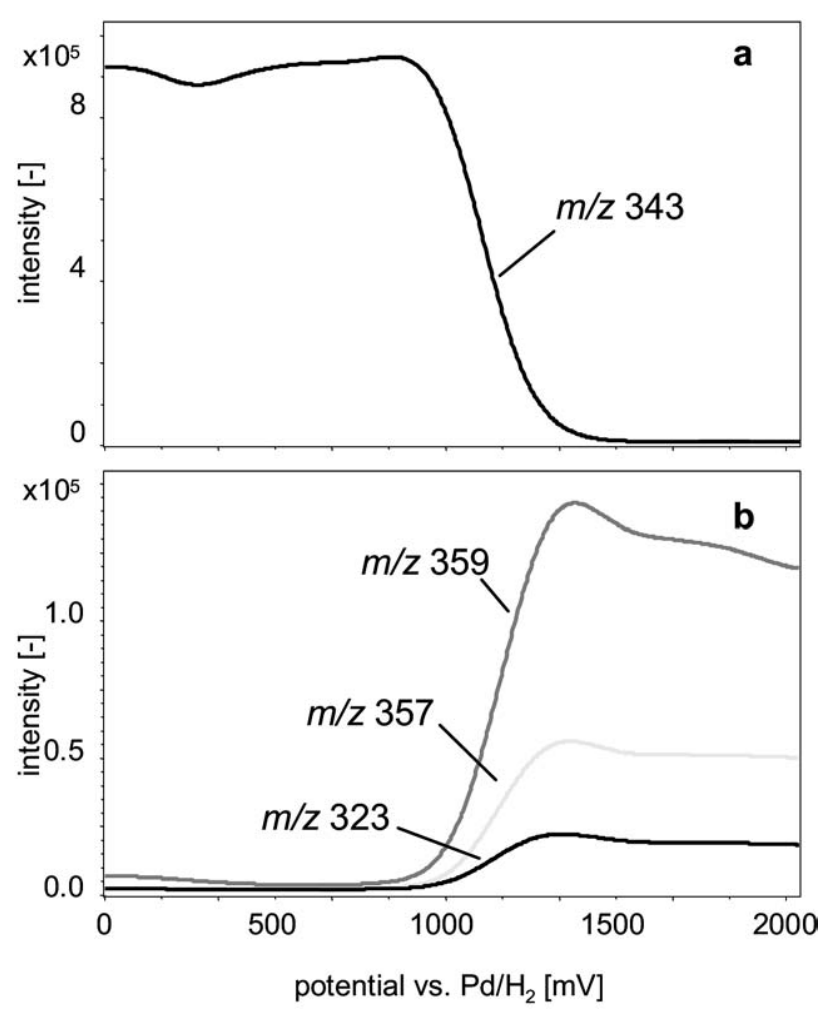

Figure 2. Ion intensities of boscalid (a) and three main oxidation products $(\mathbf{b})$ depending on the oxidation potential. The potential was ramped from 0 to $2000 \mathrm{mV}$ versus $\mathrm{Pd} / \mathrm{H}_{2}$ during $12 \mathrm{~min}$.

at $1500 \mathrm{mV}$ versus $\mathrm{Pd} / \mathrm{H}_{2}$. Apparently, boscalid is mainly oxidized by introduction of one atom of oxygen, as can be concluded from the most intense signal at $m / z 359.03,427$, which corresponds to a mass gain of $15.99,460 \mathrm{Da}$ (theoretical value for oxygen: $15.99,491 \mathrm{Da})$, potentially being a hydroxylated product or an $\mathrm{N}$-oxide. Furthermore, a signal at $\mathrm{m} / \mathrm{z} 357.01,973$ was detected, which indicates a two-step oxidation process, involving first hydroxylation to a species with $\mathrm{m} / \mathrm{z} 359$ and further dehydrogenation under formation of a quinoid species. This is only possible if boscalid was hydroxylated in ortho- or para-position in respect to the amide substitution site of ring $B$ (Scheme 1). An additional major oxidation product was detected at $\mathrm{m} / \mathrm{z}$ $323.05,697$ corresponding to a species in which $\mathrm{Cl}$ was substituted by a hydroxyl group and which was subsequently dehydrogenated. Further oxidation products of boscalid were detected in the range of $m / z$ 680-780 (Figure 3, insert b); they are dimeric boscalid-related species as can further be concluded from the isotopic pattern with the chlorine isotopomer second lowest in mass $\left({ }^{35} \mathrm{Cl}_{3}{ }^{37} \mathrm{Cl}_{1}\right)$ being the most intense one. In Figure $2 b$, the formation of the main monomeric oxidation products of boscalid with $m / z 359,357$, and 323 is presented depending on the oxidation potential. As was already observed from the depletion of boscalid (Figure $2 \mathrm{a})$, the oxidation and therewith the formation of the monomeric oxidation products starts around $1000 \mathrm{mV}$. From $1300 \mathrm{mV}$, a steady-state is reached and the signal intensity of the oxidation products stays constant. Therefore, an oxidation potential of $1500 \mathrm{mV}$ versus $\mathrm{Pd} / \mathrm{H}_{2}$ was selected for further studies.

\section{Identification of the Oxidation Products}

To obtain more information about the nature of the electrochemical oxidation products, an HPLC separation was carried out using a $\mathrm{RP}-\mathrm{C}_{18}$ column. The EC oxidation was performed before the injection to be able to optimize EC and HPLC conditions independently as was discussed elsewhere in more detail [18]. Briefly, a boscalid standard solution adjusted to physiological $\mathrm{pH}$ was pumped through the EC cell using a syringe pump at a constant flow rate of $10 \mu \mathrm{L} / \mathrm{min}$ as already described for the EC/MS measurements. The effluent was collected in an injection loop which was mounted on a 10-port switching valve. By switching the valve, the loop content is flushed by the HPLC pumps onto the column. A schematic set-up of this system is shown in Figure $1 \mathrm{~b}$ (flow path A). The base peak chromatogram of boscalid after oxidation at $1500 \mathrm{mV}$ versus $\mathrm{Pd} / \mathrm{H}_{2}$ and the extracted ion traces of the most abundant oxidation products are shown in Figure 4 . The exact masses of the compounds are provided in Table 2. Boscalid itself (peak A) is eluted at 9.2 min. Peak B has an $m / z$ ratio of $359.03,427$, corresponding to the introduction of one atom of oxygen into the boscalid moiety. Since this compound is more polar than boscalid itself, it possibly is a hydroxylated species.

By comparing the fragment ion spectra of unmodified boscalid and of peak B (Supplemental Figure 2a and $b$ ), it was concluded that the biphenyl moiety (ring $B$ or ring C) was modified because cleavage of the amide bond reveals an unmodified ring $\mathrm{A}(\mathrm{m} / \mathrm{z} 140$ in both spectra). Since at ring B and C hydroxylation is the most probable way of oxygen introduction, it was concluded that peak $B$ results from hydroxylated boscalid. This electrochemical reaction is in good accordance with the in vivo metabolism of boscalid, where hydroxylated boscalid was detected as well. The exact origin of peak B was finally assigned by means of an authentic standard of a boscalid derivative that bears a hydroxyl function in para-position (relative to the amido nitrogen) of ring B. Retention times and fragment ion spectra of Compound B and p-hydroxy boscalid were in

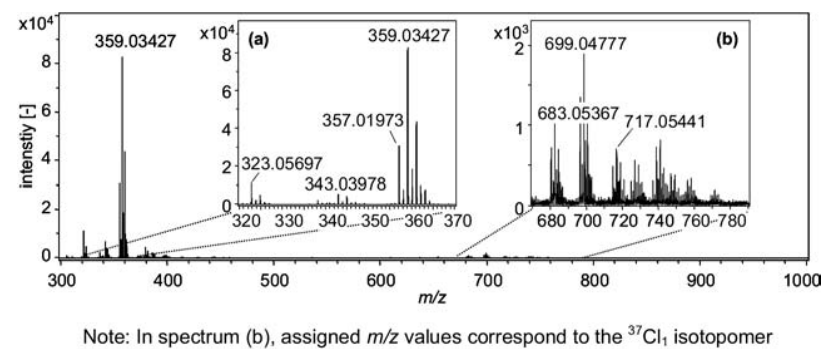

Figure 3. ESI(+)-time-of-flight mass spectrum of boscalid after oxidation at $1500 \mathrm{mV}$ versus $\mathrm{Pd} / \mathrm{H}_{2}$. 

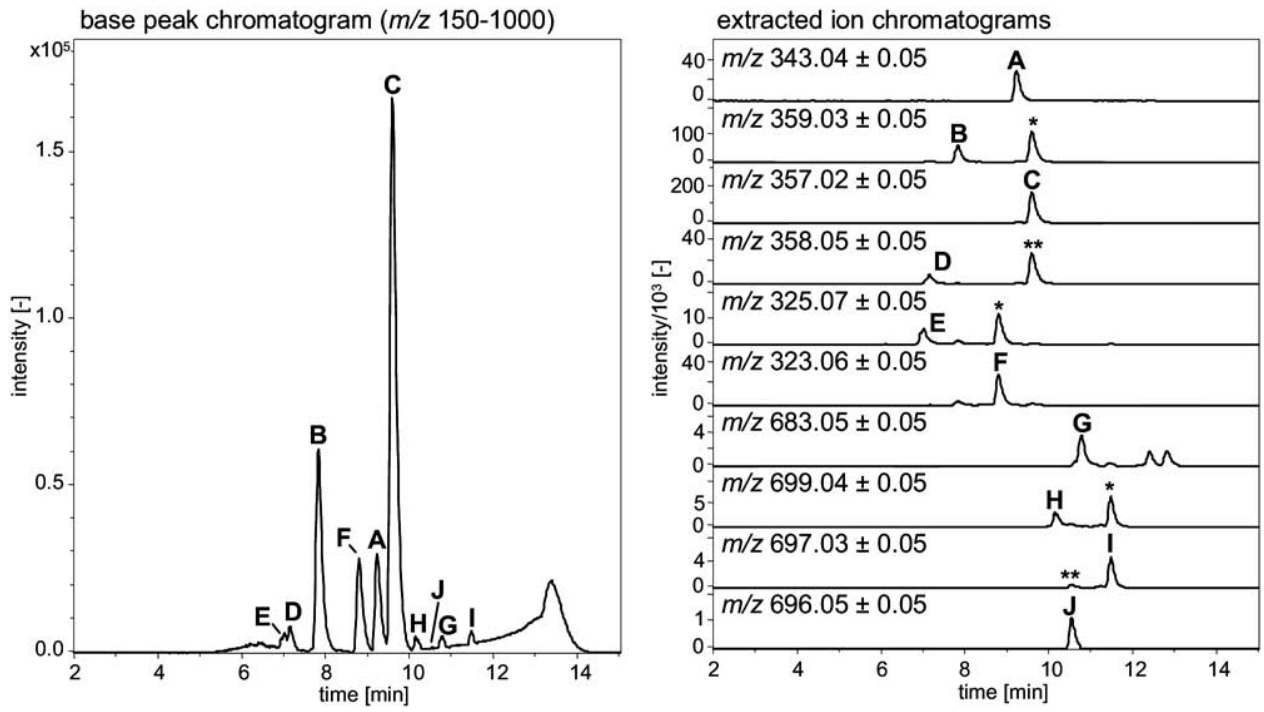

Figure 4. Base peak chromatogram $(\mathrm{m} / \mathrm{z} 150-1000)$ and extracted ion chromatograms of the separation of boscalid oxidation products. The peaks marked with one asterisk are the respective ${ }^{37} \mathrm{Cl}$ isotopomers of the compound with a mass of $2 \mathrm{u}$ less, the peak marked with two asterisks is a ${ }^{13} \mathrm{C}$ isotopomer of the compound with a mass of $1 \mathrm{u}$ less.

good accordance; hence species B is boscalid which is hydroxylated in para-position of ring B.

The most abundant peak in the base peak chromatogram of electrochemically oxidized boscalid is peak C (Figure 4), which has an $\mathrm{m} / \mathrm{z}$ value of $357.01,973$ for the $[\mathrm{M}+\mathrm{H}]^{+}$. This corresponds to a loss of two hydrogen atoms compared with hydroxylated boscalid. Therefore, peak $\mathrm{C}$ might correspond to a quinoid species, which is further supported by the fact that it is eluted later (therefore being less polar) than hydroxylated boscalid. The formation of a quinoid species provides some information about the position of the hydroxylation. Hydroxylation of ring A was excluded, since such a product cannot easily undergo dehydrogenation and furthermore, the fragment ion spectrum of Compound $\mathrm{C}$ shows the unmodified ring A with $\mathrm{m} / \mathrm{z} 140$ (Supplemental Figure 2c).

Hydroxylation of the biphenyl moiety can easily yield a quinoneimine if hydroxylation occurs in orthoor para-position to the amide substitution site of ring $\mathrm{B}$. Hence, species $C$ is the respective $o$ - or $p$-quinoneimine of hydroxy boscalid. This quinoid species was not found in in vivo experiments; however, this does not necessarily mean that it is not formed under cytochrome P450 catalysis. In vivo, quinoid species are often trapped and detoxified by addition of GSH [23], and the fact that hydroxylated GSH adducts were found in vivo might suppose that these can also be formed via a quinoneimine and not necessarily after epoxide formation as reported before [22].

An interesting observation is the formation of peak $D$ with an $\mathrm{m} / \mathrm{z}$ of $358.05,057$. The mass gain of about $15 \mathrm{Da}$ compared to boscalid does not seem to arise from a conventional metabolic or oxidation reaction; but from the exact mass gain of $15.01,090 \mathrm{Da}$, it can be concluded that one nitrogen atom and one hydrogen atom were introduced into boscalid. This reaction seems still to be unusual, but it might be possible if boscalid which was oxidized by abstraction of one electron (thus being a radical species) reacts with ammonia, which is present in the solution at a relatively high concentration level. In this case, boscalid bearing an additional amino group

Table 2. Retention times and accurate masses of the $[\mathrm{M}+\mathrm{H}]^{+}$of the boscalid oxidation products

\begin{tabular}{cccccc}
\hline Peak & Retention time & Monoisotopic $\mathrm{m} / \mathrm{z}$ & Empirical formula & Relative error & Absolute error \\
\hline \hline $\mathrm{A}$ & $9.2 \mathrm{~min}$ & 343.039784 & $\mathrm{C}_{18} \mathrm{H}_{13} \mathrm{Cl}_{2} \mathrm{~N}_{2} \mathrm{O}_{1}$ & $0.470 \mathrm{ppm}$ & $0.161 \mathrm{mu}$ \\
$\mathrm{B}$ & $7.8 \mathrm{~min}$ & 359.034272 & $\mathrm{C}_{18} \mathrm{H}_{13} \mathrm{Cl}_{2} \mathrm{~N}_{2} \mathrm{O}_{2}$ & $1.635 \mathrm{ppm}$ & $0.588 \mathrm{mu}$ \\
$\mathrm{C}$ & $9.6 \mathrm{~min}$ & 357.019729 & $\mathrm{C}_{18} \mathrm{H}_{11} \mathrm{Cl}_{2} \mathrm{~N}_{2} \mathrm{O}_{2}$ & $1.456 \mathrm{ppm}$ & $0.520 \mathrm{mu}$ \\
$\mathrm{D}$ & $7.1 \mathrm{~min}$ & 358.052173 & $\mathrm{C}_{18} \mathrm{H}_{14} \mathrm{Cl}_{2} \mathrm{~N}_{3} \mathrm{O}_{1}$ & $3.712 \mathrm{ppm}$ & $1.329 \mathrm{mu}$ \\
$\mathrm{E}$ & $7.0 \mathrm{~min}$ & 325.075110 & $\mathrm{C}_{18} \mathrm{H}_{14} \mathrm{Cl}_{1} \mathrm{~N}_{2} \mathrm{O}_{2}$ & $3.932 \mathrm{ppm}$ & $1.278 \mathrm{mu}$ \\
$\mathrm{F}$ & $8.8 \mathrm{~min}$ & 323.056966 & $\mathrm{C}_{18} \mathrm{H}_{12} \mathrm{Cl}_{1} \mathrm{~N}_{2} \mathrm{O}_{2}$ & $3.764 \mathrm{ppm}$ & $1.216 \mathrm{mu}$ \\
$\mathrm{G}$ & $10.8 \mathrm{~min}$ & 683.053667 & $\mathrm{C}_{36} \mathrm{H}_{23} \mathrm{Cl}_{4} \mathrm{~N}_{4} \mathrm{O}_{2}$ & $4.826 \mathrm{ppm}$ & $3.296 \mathrm{mu}$ \\
$\mathrm{H}$ & $10.2 \mathrm{~min}$ & 699.047774 & $\mathrm{C}_{36} \mathrm{H}_{23} \mathrm{Cl}_{4} \mathrm{~N}_{4} \mathrm{O}_{3}$ & $5.871 \mathrm{ppm}$ & $4.104 \mathrm{mu}$ \\
$\mathrm{I}$ & $11.5 \mathrm{~min}$ & 697.029765 & $\mathrm{C}_{36} \mathrm{H}_{21} \mathrm{Cl}_{4} \mathrm{~N}_{4} \mathrm{O}_{3}$ & $9.723 \mathrm{ppm}$ & $6.463 \mathrm{mu}$ \\
$\mathrm{J}$ & $10.5 \mathrm{~min}$ & 696.047780 & $\mathrm{C}_{36} \mathrm{H}_{22} \mathrm{Cl}_{4} \mathrm{~N}_{5} \mathrm{O}_{2}$ & $6.368 \mathrm{ppm}$ & $4.432 \mathrm{mu}$ \\
$\mathrm{K}$ & $6.1 / 6.2 / 6.6 \mathrm{~min}$ & 664.101731 & $\mathrm{C}_{28} \mathrm{H}_{28} \mathrm{Cl}_{2} \mathrm{~N}_{5} \mathrm{O}_{8} \mathrm{~S}_{1}$ & $1.933 \mathrm{ppm}$ & $1.284 \mathrm{mu}$ \\
\hline
\end{tabular}


is formed. This proposed mechanism provides interesting information on the formation of hydroxylated boscalid which consequently might also be formed after reaction of a radical species with water molecules in the solution.

Beside these compounds, two species (E and F) are formed upon oxidation. They both bear only one chlorine atom and one additional oxygen atom compared to boscalid. Most likely, one chlorine atom has been exchanged by a hydroxyl function in these compounds, for species $\mathrm{F}$ with $\mathrm{m} / \mathrm{z} 323$ additionally combined with the loss of two hydrogen atoms. As fragmentation experiments of Compound E with $\mathrm{m} / \mathrm{z} 325$ show (Supplemental Figure 2d), this exchange has occurred at ring $\mathrm{C}$ and not at ring $\mathrm{A}$, since the fragment of ring $\mathrm{A}$ after cleavage of the amide function still has $m / z 140$. In case of exchange of the chlorine atom of ring $\mathrm{A}$, the respective fragment would show an $\mathrm{m} / \mathrm{z}$ ratio of 122 . The formation of Compound $F$ which is a dehydrogenated species argues for the exchange of the chlorine atom at ring $C$ as well since this oxidation product can easily be dehydrogenated.

The dimeric species G, H, I, and J are all less polar than boscalid itself, thus eluting later in the chromatogram. The dimerization might also occur after oneelectron oxidation of boscalid and formation of a boscalid radical. While Compound $\mathrm{G}$ is a nonmodified boscalid dimer, Compound $\mathrm{H}$ is a hydroxylated dimer, Compound I a respective quinoid species, and Compound $\mathrm{J}$ a dimer that has an additional amino group and is dehydrogenated. The respective nondehydrogenated species with $\mathrm{m} / \mathrm{z} 698$ could not be detected. Dimers were not found in metabolism trials; apparently they can only be formed at concentrations of boscalid present in the electrochemical experiment set-up but not under physiological conditions.

\section{Two-Dimensional Electrochemistry}

For further insight into the oxidation mechanism of boscalid, a second electrochemical cell was mounted between the first cell and the injection loop which was set to a reductive potential of $-1000 \mathrm{mV}$ (Figure $1 \mathrm{~b}$, flow path B). This set-up was used to confirm the quinoid nature of some oxidation products. The base peak chromatogram and the extracted ion traces of the HPLC separation of the reduced oxidation products of boscalid are shown in Figure 5. It can nicely be seen that the complexity of the chromatogram is drastically reduced compared to the set-up without reduction (Figure 4). The main peaks are Compound A (boscalid itself), Compound B (hydroxylated boscalid), and Compound D (amino-substituted boscalid). No additional peaks, i.e., peaks not detected in the prior set-up without reduction, were observed.

The most intense peak in the chromatogram from Figure 4, the quinoid species $C$, could not be detected in this set-up at all (Figure 5), hence it had completely been reduced. Since quinoid species react to the respec-

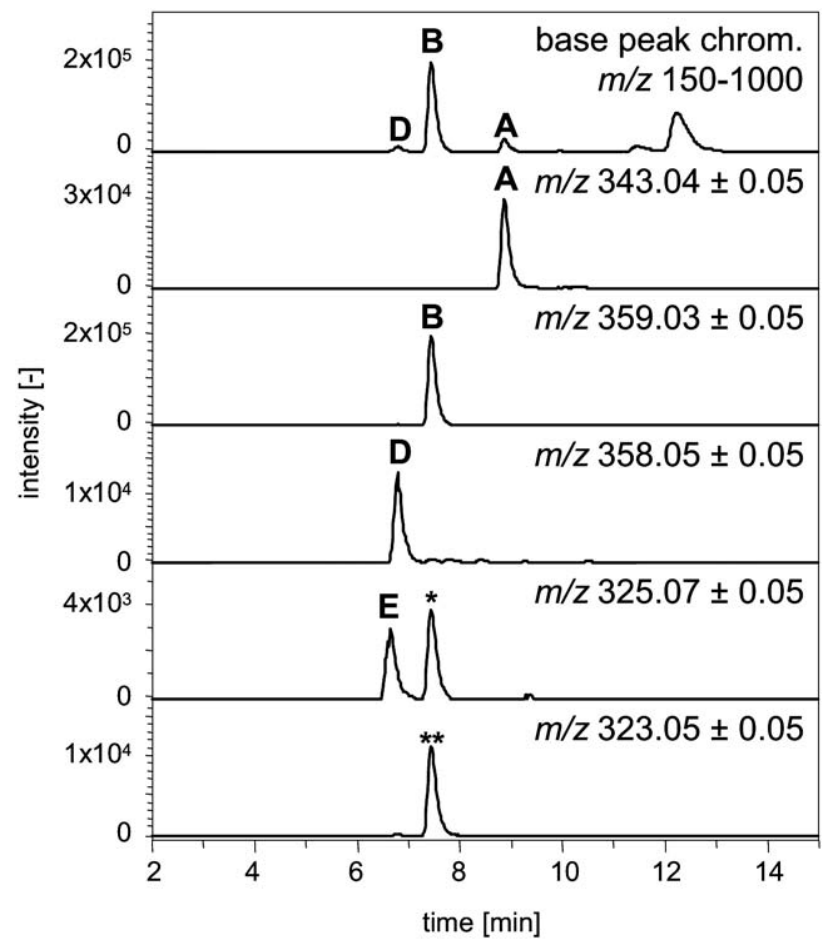

Figure 5. Base peak chromatogram $(m / z$ 150-1000) and extracted ion chromatograms of the separation of boscalid oxidation products after reduction. The peaks marked with one asterisk are the respective ${ }^{37} \mathrm{Cl}$ isotopomers of the compound with a mass of $2 \mathrm{u}$ less; the peaks marked with two asterisks result from in-source fragmentation.

tive hydroquinone compounds when they are reduced, Compound $C$ should have an $\mathrm{m} / \mathrm{z}$ ratio of 359 after reduction like Compound B. However, in the extracted ion trace of $\mathrm{m} / \mathrm{z}$ 359.03, no additional peak beside Compound B is detectable, whereas the intensity of Compound B is obviously higher than without reduction. Hence, Compound $\mathrm{C}$ was reduced to Compound $\mathrm{B}$ in the second electrochemical cell. Since Compound B is $p$-hydroxy boscalid, also species $C$ is hydroxylated in para-position of ring $\mathrm{B}$ with respect to the amide substitution site. Apparently, Compound B was not completely dehydrogenated to the respective quinoneimine $\mathrm{C}$ in the previous set-up without reduction.

These observations were further confirmed by an experiment in which the authentic standard of $p$-hydroxy boscalid was oxidized in the EC cell. A quinoid species with $\mathrm{m} / \mathrm{z} 357$ was formed that showed the same retention time and fragmentation pattern as Compound C. Thus it was additionally affirmed that Compound $\mathrm{C}$ is the $p$-quinoneimine of boscalid.

Almost no difference in the intensities of Compound $\mathrm{D}$ with and without reduction could be observed. The reaction of the radical cation with ammonia is thus much faster than the following reduction and is terminated before the second EC cell is reached. Compounds $\mathrm{E}$ and $\mathrm{F}$ have structures analogous with species $\mathrm{B}$ and $\mathrm{C}$, since no additional peak in the $\mathrm{m} / \mathrm{z} 325$ trace was observed and no quinoid species F with $\mathrm{m} / \mathrm{z} 323$ was 
detected after reduction. Therefore, it was concluded that Compound F was converted to Compound E upon reduction.

\section{Conjugative Metabolism}

To obtain information on the phase II metabolism of boscalid, a tenfold excess of GSH relative to boscalid was added via a T-piece after the EC cell in which the oxidation of boscalid was performed (Figure 1b, flow path $\mathrm{C}$ ). As can be seen from Figure 6, three additional peaks with $\mathrm{m} / \mathrm{z} 664.10,173$ of which the two first eluting are not very well resolved, appear in the chromatogram, whereas the quinoneimine $C$ is not present anymore. Therefore, it was concluded that the quinoneimine $\mathrm{C}$ was completely trapped by GSH, and three isomeric GSH adducts with $\mathrm{m} / \mathrm{z}$ 664.10,173 were formed. Since Compound F was also identified as dehydrogenated species, the formation of a respective GSH adduct with $\mathrm{m} / \mathrm{z} 630$ should be observed. However, no such compound was detected.

A species with $m / z 614$ should be formed if GSH directly substitutes the chlorine atom of ring $\mathrm{A}$, as was described before ([22], Scheme 1). This was not observed in the EC/LC/MS set-up, presumably because the reaction time of oxidized boscalid and GSH is extremely short in the EC experiments compared to in vivo studies. If boscalid was not oxidized before reaction with GSH, no covalent adduct formation was observed. In in vivo or standard in vitro experiments, the reaction time is much longer and nucleophilic substitution can occur. No change in the extracted ion trace of hydroxylated boscalid was observed with and without addition of GSH. This was to be expected since GSH reacts nucleophilically only with reactive species such as quinoid compounds, epoxide, or radicals. When the oxidation products of boscalid were reduced before reaction with GSH, no GSH adducts were detectable since no quinoid reactants were present in the mixture.

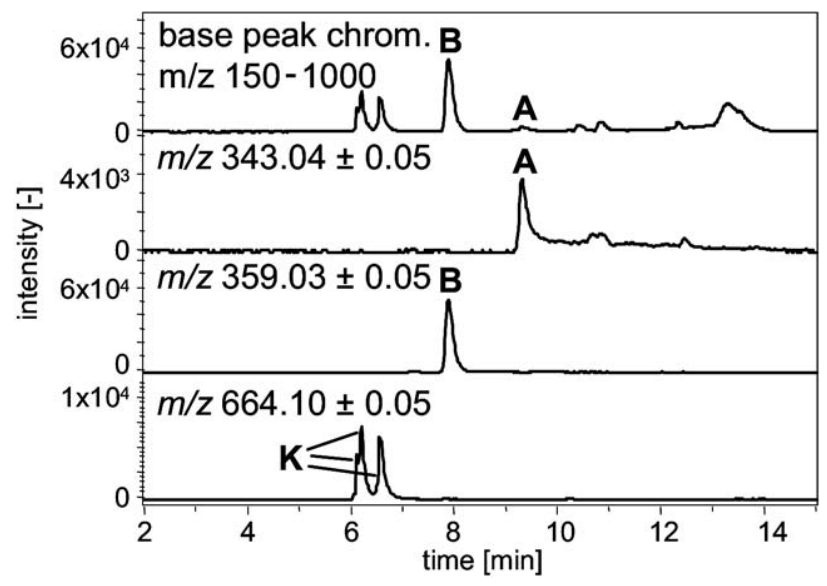

Figure 6. Base peak chromatogram $(m / z$ 150-1000) and extracted ion chromatograms of the separation of boscalid oxidation products after reaction with glutathione.

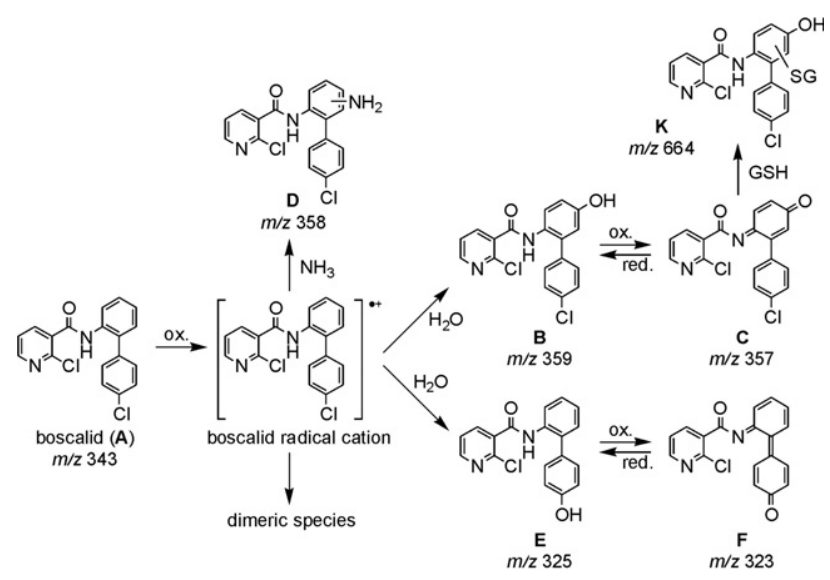

Scheme 2. Electrochemical reaction scheme of boscalid at 1500 $\mathrm{mV}$ at $\mathrm{pH} 7.4$.

\section{Electrochemical Oxidation Pathway of Boscalid}

Scheme 2 summarizes the electrochemical oxidation behavior of boscalid at $1500 \mathrm{mV}$ at $\mathrm{pH}$ 7.4. After a one-electron oxidation step, a boscalid radical cation is formed, which subsequently reacts with either one water molecule, with ammonia from the buffer system, or with another boscalid molecule. While after reaction with ammonia, amino substituted boscalid (D) is formed, and after reaction with another oxidized or nonoxidized boscalid molecule dimeric species are generated, the reaction with water leads to hydroxylated boscalid.

The hydroxylation occurs by substitution of one hydrogen atom (yielding Compound B) or the chlorine atom (resulting in Compound E) of the biphenyl ring system. In both cases, further oxidation to the respective quinoid species occurs (species $\mathrm{C}$ and F). The quinoid Compound $\mathrm{C}$ is reactive towards GSH as trapping agent, and three isomeric covalent GSH adducts $\mathrm{K}$ were formed as could be theoretically expected. The results of the electrochemical oxidation experiments of boscalid are in good agreement with the previously reported in vivo metabolism. In those experiments, hydroxylated boscalid and isomeric GSH adducts were observed as well. However, while in the in vivo experiments, it remains unclear if the GSH adducts are formed via an arene oxide or a quinoid species, it is proven by the direct detection of Compound $\mathrm{C}$ that in the EC set-up the GSH adducts are generated after formation of a quinoid compound. The formation of the amino-substituted boscalid and the dimeric species in the electrochemical experiments, however, reveals the mechanistic difference between electrochemical and cytochrome P450 catalyzed oxidation reactions since the oxidation of boscalid to a radical cation, which results in the formation of dimeric species and amino substituted boscalid, is unlikely to occur under cytochrome P450 catalysis. However, an interesting similarity between both experiments could be observed concerning Compound E: In the in vivo experiments, a glucuronic acid 
conjugate at the former chlorine position of ring $\mathrm{C}$ as well as a $\gamma$-glutamylcysteine conjugate with chlorine lost at this position were detected. This confirms the reactivity of this position towards hydrolysis and nucleophilic substitution as was also observed for the electrochemical oxidation.

\section{Conclusions}

In this work, the electrochemical simulation of the oxidative metabolism of a pesticide was presented for the first time. In previous work, the focus of this technique was exclusively directed towards pharmaceutical drug metabolism. It was shown that the electrochemical oxidation of boscalid yielded similar products as were found after in vivo metabolism. In both cases, hydroxylated species as well as isomeric covalent GSH adducts were formed. To unravel the nature of the metabolites, an EC/LC/MS set-up comprising two electrochemical cells was introduced. In the first cell, the oxidative metabolism was simulated while in the second cell the quinoid oxidation products were reduced. From this set-up, more information on the regioselectivity of the oxidation was accessible. All experiments were performed using high-resolution mass spectrometry, which provides more insight into the nature of the oxidation products. Even if differences in the mechanism of the metabolite formation in EC and in vivo experiments cannot be dismissed, the results of both oxidations were well comparable. To sum up, it could be shown that the hyphenation of different electrochemical experiments with LC/MS is a useful tool in the rapid investigation of the oxidative metabolism of not only pharmaceuticals, but also other xenobiotics such as the pesticide boscalid.

\section{Acknowledgments}

The authors gratefully acknowledge financial support by the Deutsche Forschungsgemeinschaft (DFG, Bonn, Germany) and the Fonds der Chemischen Industrie (Frankfurt, Germany).

\section{References}

1. Hambitzer, G.; Heitbaum, J. Electrochemical Thermospray Mass Spectrometry. Anal. Chem. 1986, 58, 1067-1070.
2. Volk, K. J.; Lee, M. S.; Yost, R. A.; Brajter-Toth, A. Electrochemistry/ Thermospray/Tandem Mass Spectrometry in the Study of Biooxidation of Purines. Anal. Chem. 1988, 60, 720-722

3. Volk, K. J.; Yost, R. A.; Brajter-Toth, A. Characterization of Solution-Phase and Gas-Phase Reaction in On-Line Electrochemistry-Thermospray Tandem Mass Spectrometry. J. Chromatogr. 1989, 474, 231-243.

4. Volk, K. J.; Yost, R. A.; Brajter-Toth, A. On-Line Electrochemistry/ Thermospray/Tandem Mass Spectrometry as a New Approach to the Study of Redox Reactions: The Oxidation of Uric Acid. Anal. Chem. 1989, 61, 1709-1717.

5. Volk, K. J.; Yost, R. A.; Brajter-Toth, A. Online Mass Spectrometric Insights into Electrochemical Reactions: Oxidation of Thiopurines. I. Electrochem. Soc. 1990, 137, 1764-1771.

6. Shono, T.; Toda, T.; Oshino, N. Preparation of N-Dealkylated Drug Metabolites by Electrochemical Simulation of Biotransformation. Drug Metab. Dispos. 1981, 9, 481-482.

7. Shono, T.; Toda, T.; Oshino, N. Electron Transfer from Nitrogen in Microsomal Oxidation of Amine and Amide. Simulation of Microsomal Oxidation by Anodic Oxidation. J. Am. Chem. Soc. 1982, 104, 2639-2641.

8. Hall, L. R.; Iwamoto, R. T.; Hanzlik, R. P. Electrochemical Models for Cytochrome P-450. N-Demethylation of Tertiary Amides by Anodic Oxidation. J. Org. Chem. 1989, 54, 2446-2451.

9. Hall, L. R.; Hanzlik, R. P. Kinetic Deuterium Isotope Effects on the N-Demethylation of Tertiary Amides by Cytochrome P-450. J. Biol. Chem. 1990, 265, 12349-12355.

10. Getek, T. A.; Korfmacher, W. A.; McRae, T. A.; Hinson, J. A. Utility of Solution Electrochemistry Mass Spectrometry for Investigating the Formation and Detection of Biologically Important Conjugates of Acetaminophen. J. Chromatogr. A 1989, 474, 245-256.

11. Jurva, U.; Wikström, H. V.; Bruins, A. P. In vitro Mimicry of Metabolic Oxidation Reactions by Electrochemistry/Mass Spectrometry. Rapid Commun. Mass Spectrom. 2000, 14, 529-533.

12. Jurva, U.; Wikström, H. V.; Weidolf, L.; Bruins, A. P. Comparison Between Electrochemistry/Mass Spectrometry and Cytochrome P450 Catalyzed Oxidation Reactions. Rapid Commun. Mass Spectrom. 2003, 17 , $800-810$.

13. Gamache, P. H.; Smith, R.; McCarthy, R.; Waraska, J.; Acworth, I. N. ADME/Tox Profiling: Using Coulometric Electrochemistry and Electrospray Ionization Mass Spectrometry. Spectroscopy 2003, 18, 14-41.

14. Gamache, P. H.; Meyer, D. F.; Granger, M. C.; Acworth, I. N. Metabolomic Applications of Electrochemistry/Mass Spectrometry. J. Am. Soc. Mass Spectrom. 2004, 15, 1717-1726.

15. Van Leeuwen, S. M.; Blankert, B.; Kauffmann, J.-M.; Karst, U. Prediction of Clozapine Metabolism by On-Line Electrochemistry/ Liquid Chromatography/Mass Spectrometry. Anal. Bioanal. Chem. 2005, 382, 742-750.

16. Lohmann, W.; Karst, U. Simulation of the Detoxification of Paracetamol Using On-Line Electrochemistry/Liquid Chromatography/Mass Spectrometry. Anal. Bioanal. Chem. 2006, 386, 1701-1708.

17. Madsen, K. G.; Olsen, J.; Skonberg, C.; Hansen, S. H.; Jurva, U. Development and Evaluation of an Electrochemical Method for Studying Reactive Phase-I Metabolites: Correlation to in Vitro Drug Metabolism. Chem. Res. Toxicol. 2007, 20, 821-831.

18. Lohmann, W.; Karst, U. Generation and Identification of Reactive Metabolites by Electrochemistry and Immobilized Enzymes Coupled On-Line to Liquid Chromatography/Mass Spectrometry. Anal. Chem. 2007, 79, 6831-6839.

19. Karst, U. Electrochemistry/Mass Spectrometry-A New Tool to Study Drug Metabolism and Reaction Mechanisms. Angew. Chem. Int. Ed. 2004, 43, 2476-2478.

20. Permentier, H. P.; Bruins, A. P.; Bischoff, R. Electrochemistry-Mass Spectrometry in Drug Metabolism and Protein Research. Mini Rev. Med. Chem. 2008, 8, 46-56.

21. Lohmann, W.; Karst, U. Biomimetic Modeling of Oxidative Drug Metabolism. Anal. Bioanal. Chem. 2008, 391, 79-96.

22. Levsen, K.; Schiebel, H.-M.; Behnke, B.; Dötzer, R.; Dreher, W.; Elend M.; Thiele, H. Structure Elucidation of Phase II Metabolites by Tandem Mass Spectrometry: An Overview. J. Chromatogr. A 2005, 1067, 55-72.

23. Rinaldi, R.; Eliasson, E.; Swedmark, S.; Morgenstern, R. Reactive Intermediates and the Dynamics of Glutathione Transferases. Drug Metab. Dispos. 2002, 30, 1053-1058. 